\title{
De la respuesta a la locura, a la locura como respuesta.
}

From the answer to madness and madness as an answer.

\author{
Carlos Jesús Rodríguez Rodríguez-Caro ${ }^{\mathrm{a}}$, Dulcinea Vega Dávila ${ }^{\mathrm{b}}$, Mónica Florido Rodríguez \\ Cristina Ascensión Godoyd.
}

${ }^{a}$ MIR Psiquiatría, Complejo Hospitalario Universitario Insular Materno Infantil de Gran Canaria, Las Palmas de Gran Canaria, España. ${ }^{b}$ Psiquiatra, Complejo Hospitalario Universitario Insular Materno Infantil de Gran Canaria, Las Palmas de Gran Canaria, España. ${ }^{c}$ MIR Psiquiatría, Complejo Hospitalario Universitario Insular Materno Infantil de Gran Canaria, Las Palmas de Gran Canaria, España. ${ }^{d P}$ siquiatra, Complejo Hospitalario Universitario Insular Materno Infantil de Gran Canaria, Las Palmas de Gran Canaria, España.

Correspondencia: Carlos Jesús Rodríguez Rodríguez-Caro (rguezrguezcaro@hotmail.com)

Recibido: 29/12/2012; aceptado: 20/05/2013

RESUMEN: Se presenta el caso clínico de una mujer de cuarenta años de edad que es atendida en el Servicio de Urgencias (por recomendación de su hija) al contactar con su difunto cuñado, y sentirlo "como si estuviera dentro de ella". La paciente comentó que el fallecido le había trasmitido que deseaba que su viuda rehiciera su vida de pareja y familiar. Durante la observación psicopatológica se aprecia, entre otros datos, verbalizaciones de ideas de perjuicio. La hija de la paciente especifica reiteradamente que existía una asociación entre la toma de tratamiento anticonceptivo con dispositivo intrauterino hormonal (levonorgestrel) y síntomas premórbidos (caracterizados por apatía, abulia y abandono parcial de sus tareas cotidianas). Se planteó el diagnóstico diferencial entre un trastorno psicótico de debut o un trastorno disociativo, a descartar una posible inducción del tratamiento hormonal. La evolución clínica y el conocimiento de la situación vital de la paciente permitirá discernir el cuadro.

PALABRAS CLAVE: Acontecimientos que Cambian la Vida. Trastornos Disociativos. Trastornos Psicóticos. Taxonomía.
ABSTRACT: A case involving a 40-years old woman attended by the Emergency Service (at the request of her daughter). The woman claimed she had had contact with her late brother-in-law and felt "as if he had been inside her". The patient also said that the deceased had expressed his desire to see his widow recover her intimate personal and family life. During the psychopathological observation, vocalizations of prejudicial ideas, among other data, were noted. The patient's daughter repeatedly specified an association between the intake of contraceptive treatment with hormonal intrauterine device (levonorgestrel) and premorbid symptoms (characterized by apathy, abulia and partial abandonment of her routine activities). A differential diagnosis was proposed among which, a psychotic disorder, a dissociative disorder, or a possible induction by the hormonal treatment, was presented. The clinical progress and the knowledge of the patient's vital situation will help determine the clinical picture.

KEY WORDS: Life Change Events. Dissociative Disorders. Psychotic Disorders. Classification. 


\section{Presentación:}

Finalizo mi rotación en Psiquiatría Comunitaria, y con ello su acompañamiento ambulatorio tras un primer ingreso en la Unidad de Agudos. Peinada con raya en medio, recoge su flequillo con pinzas de colores. Llamativa e infantil para ser una mujer de cuarenta años. Numerosas pulseras de diferentes tamaños, formas y colores adornan sus muñecas. - ¿¿Le gustan doctor? Las hago yo misma para evadirme de todo lo que ha pasado" (sic). Tiene un trato interpersonal adecuado, a la vez que jocoso. Dicharachera y extrovertida. Siempre que salgo a recibirla a la sala de espera, está hablando con otro paciente o familiar. Me impresiona que, en ocasiones, juega un papel burlón de inocente poco cualificada de dotes intelectuales. Le encanta bromear con esta imagen.

Nos conocimos hace meses en el Servicio de Urgencias. Acudió acompañada por su hija, la cual estaba muy alarmada. No era para menos: la paciente le había comentado que vio y habló con su difunto cuñado; y días posteriores se había comportado en tres ocasiones "como si el cuñado estuviera dentro de ella". Fueron episodios recortados en el tiempo, con inicio y final bruscos, en los que presentaba un tono de voz grave y varonil, mirada perdida, y escasa gesticulación. Con cierta indiferencia afectiva, la paciente afirmaba con absoluta convicción tales sucesos. Excepto el olor a tabaco en sus manos, el resto de acontecimientos durante los episodios no los recordaba. De forma enigmática, nos confesó el mensaje que debía trasmitir a su hermana de parte del fallecido: -"Siento mucho no poder haberte dado hijos. Quiero que te busques un hombre y que adoptes un niño africano" (sic). Si la paciente tuviera que destacar alguna virtud de su cuñado (al cual definió como un empedernido fumador), lo haría del amor y protección con que trató a su hermana. La hija agregó que su madre, en los periodos intercríticos, predecía que su cuñado se la llevaría al cielo y verbalizaba temores a una muerte inminente.

Los antecedentes personales fueron recogidos gracias a la hija, ya que la paciente respondía musitando. Relataron que no tenía alergias, ni antecedentes orgánicos de interés. Datos anodinos en su gestación, parto, infancia y juventud. La hija remarcó insistentemente la asociación, desde hacía ocho meses, entre la anticoncepción con dispositivo intrauterino hormonal (levonorgestrel) e inicio de sintomatología psicopatológica. Esta última caracterizada por síndrome apato-abúlico, con abandono parcial de sus responsabilidades. Había asistido a terapia de pareja, durante dos años, en circuito privado. Como antecedentes familiares, tiene una prima diagnosticada de esquizofrenia. Ocupa el segundo lugar de una familia de seis hermanos, cuatro mujeres y dos hombres. Vive con su marido y su hija de veinte años de edad. Esta se encontraba en proceso de independencia, siendo inminente el inicio de la convivencia con su pareja. El último verano tuvo en acogida a un niño africano. Hacía tres semanas, cumplió su contrato de trabajo como limpiadora, por lo que gran parte del día se dedicaba a tareas del hogar. A la vez, empezó a practicar reiki. La familia había detectado en la paciente "aumento de la energía" tras las sesiones, y comentarios sobre la reencarnación. 
En el Servicio de Urgencias mantuvo una actitud de colaboración parcial a la exploración. Destacaba un discurso inducido, y respondía: -"usted ya lo sabe" o -"es algo confidencial, que atañe a mi cuñado y a mî́" (sic). Puntualmente se detectaron ideas de perjuicio - "la vecina nos va a denunciar por malos tratos al niño africano" (sic), por lo que se decidió el ingreso de la paciente. Inicialmente se planteó el diagnóstico diferencial entre un trastorno psicótico de debut o trastorno disociativo, a descartar posible inducción del tratamiento hormonal.

\section{Evolución:}

A la llegada a la Unidad de Agudos, persistía la clínica de forma fluctuante. Desplegó una inicial actitud mutista, expresándose a través de gesticulaciones burdas y apariencia pitiatiforme. Continuó con la presentación de episodios de trance, con intrusión de fenómenos de aparente posesión. En los que cambiaba el tono de voz por uno más grave, para reiterar que su hermana -"debía rehacer su vida con un hombre que desee darle un hijo" (sic). Aunque la paciente atribuía estas verbalizaciones a su cuñado, impresiona que eran propias y dirigidas a su marido. Durante estos episodios relataba "como si" existiera algún tipo de automatismo, pero sin la presentación franca de los fenómenos xenopáticos de las psicosis. También se asociaban ideas de perjuicio de certeza variable y escasa estructuración, hacia vecinas y compañeros de trabajo, con un fondo culposo y temor a un castigo. No se observaron fenómenos sensoperceptivos. El afecto era versátil, desde una euforia pueriliforme al contacto con otros pacientes y profesionales sanitarios en la unidad, a una tristeza reactiva congruente cuando era capaz "de ser ella misma" en el despacho. En esos momentos, donde el contacto era sintónico y la resonancia afectiva adecuada, se permitía el relato de factores estresantes, que no relaciona con la clínica. Narraba problemática conyugal secundaria a conducta adictiva del esposo: -"Yo amo a mi marido, pero él me desplaza" (sic); así como discrepancias entre ellos: su pareja deseaba un hijo biológico, y ella adoptar formalmente al niño africano que acogieron en los meses de verano. Reafirmó la anamnesis recogida por la hija, así como la impresión de relación de la clínica con el tratamiento anticonceptivo. -"Yo estoy mal, es por el DIU" (sic).

Ante la aparición brusca y atípica del cuadro, sin antecedentes conocidos, se realizó hemograma, bioquímica incluyendo función hepática, renal, tiroidea y hormonal. Por recomendación del Servicio de Neurología, el estudio se completó con TC cerebral y electroencefalograma. Los hallazgos de las pruebas complementarias no fueron significativos para la resolución del caso. Se mantuvo el tratamiento psicofarmacológico pautado desde el Servicio de Urgencias: combinación de olanzapina con benzodiacepinas, el cual se fue disminuyendo a lo largo del ingreso ante la 
sospecha diagnóstica final. Se cursó interconsulta al Servicio de Ginecología; el cual dudó de la influencia de progesterona en el cuadro, dado que la paciente había usado en otras ocasiones tratamiento hormonal. A pesar de ello, se retiró el dispositivo. Tras lo cual, asombrosamente se produjo empeoramiento psicopatológico con fluctuación afectiva y verbalizaciones de ideas de pseudociesis.

Durante el ingreso, Enfermería recogió los siguientes datos de su comportamiento: oposicionismo, rebelándose contra normas internas de la unidad, sollozos pueriliformes secundarios a identificación con situaciones de otros pacientes, somatizaciones en forma de dolor torácico, episodios de mutismo selectivo, etc. Se apreció la asociación de los episodios de trance con la presencia de mayor número de espectadores, sugestión en la consulta, y previo al horario de visitas familiares. En las entrevistas individuales, se fue precisando que las supuestas ideas delirantes correspondían a miedos ante posibles conductas ilícitas del marido. Paulatinamente, en las entrevistas familiares, salió a relucir problemática grave de pareja. La paciente reconoció planes de separación temporal, con posibilidad de retomar la relación si su marido iniciaba tratamiento para su conducta adictiva.

Los episodios disociativos empezaron a espaciarse en el tiempo. Pero se produjo un giro en el positivo curso evolutivo de la paciente, tras un gesto parasuicida del marido. Se reanudaron los fenómenos de posesión e ideas de perjuicio burdas e inconsistentes. En uno de los episodios de trance, a la vez que se le validó su malestar, se le confrontó la reactividad de estos fenómenos y se le solicitó la expresión de afectos sin la necesidad de tales estados. Seguidamente gritó: - ¿YY cómo lo digo?" (sic), remitiendo repentinamente su estado crepuscular. Reconocía temor a los cambios que podría sufrir su vida, así como sentimientos de culpa, ante la posibilidad de abandonar a su pareja: -"no sabe vivir sólo, ¿aprenderá estando yo aquí o con otro?" (sic).

A los dos meses del ingreso hospitalario, se origina la decisión familiar de denunciar al marido de la paciente por malos tratos, con obtención de orden de alejamiento: se había desvelado el secreto familiar. Desaparece la clínica desde ese momento, con persistencia de síntomas ansiosos en relación con los acontecimientos ocurridos. Se inicia elaboración y fomento de estrategias para afrontar la nueva situación, que han continuado trabajándose en el ámbito extrahospitalario.

\section{Discusión:}

En el contexto de inactividad laboral y emancipación de su hija, la paciente cuestiona su vigente etapa vital, posibles cambios y la repercusión de estos en su pareja. Podríamos plantear la hipótesis de que su clínica es la respuesta a la duda entre: 
el deseo de capacitar a su esposo "a vivir sin ella", y el de ser madre (con la adopción del niño africano o "dándole un hijo a su marido"). Así, se reflexiona sobre la asociación entre la aparición de la clínica y la instauración del dispositivo intrauterino, no ya como el efecto causal neurobiológico sospechado al inicio, sino como símbolo del conflicto referido. En la patoplastia se entrecruzan los conocimientos sobre la reencarnación de las medicinas alternativas orientales, el duelo de un familiar al que le atribuye una imagen idílica de cónyuge, y factores vitales estresantes.

El cuadro presentado se nos asemeja a las Psicosis Histéricas, o contradiciendo el término la "locura histérica" de Maleval (1). Remeda la "apropiación de la conducta psicótica" expuesta por Hirsch y Hollender (1969), que hace referencia al proceso de conversión que adopta la forma de síntomas psicóticos (2). Diagnóstico controvertido a nivel nosológico. No queda clasificada en el DSM-IV-R, y la limitación en el campo de la histeria es aún mayor para el DSM-5. En la CIE-10 está a camino entre "otros trastornos disociativos (de conversión) especificados", "otro trastorno psicótico agudo con predominio de ideas delirantes" que incluye la psicosis psicógena paranoide, y "trastorno psicótico agudo y transitorio sin especificación" en el que se incluyen las psicosis reactivas breves (3). Ante esta controversia, respondemos con la siguiente afirmación de Tiburcio Angosto: "la pasión se lleva mal con la ciencia y la histeria es apasionada". Recordando el mencionado autor, el caso incluye sus consideraciones más características sobre las psicosis histéricas (personalidad histérica, elementos relacionales impactantes cercanos en el tiempo, delirio y alucinaciones que emanan de significados esenciales de su biografía, conducta cercana a la disociación/ despersonalización, corta duración y buen insight) (4). Más recientemente, algunos autores proponen volver a etiquetar las psicosis histéricas como psicosis disociativas (5), con un diagnóstico dimensional que incluya la dimensión psicótica, afectiva y disociativa-confusional (6). En esta línea Van der Hart, Wirztum y Friedman (1993) redactan en un caso de psicosis histérica que "el episodio traumático, no se podía expresar con palabras..." (5).

\section{BIBLIOGRAFÍA:}

(1) Maleval JC. El delirio histérico no es un delirio disociado; y Esquizofrenia y locura histérica. En: Locuras Histericas y Psicosis Disociativas. $1^{\text {a }}$ ed. Buenos Aires: Paidós, 1987.

(2) Hollander MH, Hirsch S. Hysterical psychosis. Am J Psychiatry 1964;120:1066-1074.

(3) García-Valdecasas J. et al. Encuadre nosológico de la "psicosis histérica" versus psicosis agudas: Revisión a propósito de un caso. Revista de la Asociación Española de Psiquiatría, Vol. XXV, $\mathrm{N}^{\circ}$ 95, Julio/Septiembre 2005, 9-23. 
(4) Angosto T. Psicosis histérica vs esquizofrenia. Cuadernos de psiquiatría comunitaria, Vol 6, $\mathrm{N}^{\circ} 2,2006$.

(5) Witztum E, Van der Hart O. Capítulo dos: Psicosis histérica: revisión histórica y evaluación empírica. En: Moskowitz A, Schäfer I, Dorahy M. Psicosis, trauma y disociación: Nuevas perspectivas sobre la psicopatología grave. Madrid: Fundación para la Investigación y el Tratamiento de la Esquizofrenia y Otros Trastornos Psicóticos, 2008; p. 19-36.

(6) Hueso H. Psicosis Histérica o Trastorno Disociativo Psicótico: El Problema de la Nosología Psiquiátrica. Vitae: Academia Biomédica Digital, № 34, 2008. 